\title{
Uso de Ground Penetrating Radar para estudo de velocidade de ondas EM na planície costeira da Massambaba, RJ
}

Raisa Cristina Rodrigues Alves, UFF; Israeli Rodrigo Mathias dos Santos, UFF; Pedro Moutinho Vieira Campos, UFF; Guilherme Borges Fernandez, LAGEF-UFF

Copyright 2018, SBGf - Sociedade Brasileira de Geofísica

Este texto foi preparado para a apresentação no VIII Simpósio Brasileiro de Geofísica, Salinópolis, 18 a 20 de setembro de 2018. Seu conteúdo foi revisado pelo Comitê Técnico do VIII SimBGf, mas não necessariamente representa a opinião da SBGf ou de seus associados. E proibida a reprodução total ou parcial deste material para propósitos comerciais sem prévia autorização da SBGf.

\section{Resumo}

A propagação de ondas eletromagnéticas é dependente das propriedades elétricas do meio em que se propaga, quando utilizada em diferentes ambientes deposicionas. O Ground Penetrating Radar (GPR) é um método geofísico que utiliza dos conceitos de propagação de ondas eletromagnéticas para registrar não somente aspectos relacionados à arquitetura sedimentar, mas permite inferir, também, importantes indicadores de processos geológicos que geraram os acamamentos observados. A planície da Massambaba localizada no litoral do Estado do Rio de Janeiro apresenta diversos ambientes deposicionais em que as barreiras arenosas servem de substrato para investigações com georadar. A partir dos dados obtidos em modo contínuo e ponto a ponto, foi possível observar reflexões referentes ao lençol freático, formações pedogenéticas associadas a espodossolos e refletores associados à dinâmica eólica. A validação das profundidades obtidas a partir do ajuste a testemunhos rasos.

\section{Introdução}

Em termos fisiográficos, o litoral do Estado do Rio de Janeiro é marcado por planícies costeiras em que predominam a formação de barreiras costeiras arenosas, apresentando características morfológicas distintas em relação à influência fluvial, processos marinhos e desenvolvimento de formações eólicas (Fernandez e Rocha, 2015). O que foi verificado na literatura foi o comportamento do nível do mar nos últimos 7000 anos maior que o atual, havendo um máximo transgressivo holocênico e o decréscimo do nível até o atual (Ângulo et AL, 2006; Suguio et al, 1988; Martin et al, 1997). Com essas variações de nível do mar geraram a formação de duas barreiras costeiras arenosas, com lagunas entre elas, caracterizando a planície de Massambaba (Coe Neto, 1984; Muehe, 1984; Muehe e Corrêa, 1989).

A evolução das barreiras arenosas no litoral do Rio de Janeiro sugere a formação de sistemas barreira-laguna para parte do litoral, como resposta à transgressão ocorrida desde o último pós-glacial.

O aporte sedimentar predominante é de depósitos quaternários pleistocênicos e holocênicos, mais especificamente formado por depósitos eólicos. Diferentes materiais deram origem aos diferentes tipos de solo na região e estão intimamente relacionados aos fatores climáticos distintos e complexos que podem ser observados na região dos lagos.

Neste trabalho, a região de estudo a ser abordada é a Planície Costeira da Massambaba, mais especificamente em seu setor central, denominação está baseada na divisão da planície em setores dada por Figueiredo (2015). A partir de um mapeamento feito por Figueiredo (2015), foi possível notar a presença das duas barreiras, interna e externa, sendo os corpos lagunares menores, individualizados e circulares. A princípio a idade das barreiras foi dada por ${ }^{14} \mathrm{C}$ de material turfoso como holocênicas, mas, depois, fragmentos de madeira coletados nas lagunas intra-cordões por Martin e Suguio (1989, apud Muehe, 1994), situando a barreira inferior como pleistocênica.

$\mathrm{Na}$ região, existem feições associadas a episódios transgressivos, evidenciadas pelos sistemas barreiralaguna, mesmo com a atual tendência de diminuição do nível do mar a partir dos últimos 5.800 A.P (Ângulo et al. 2006; Figueiredo, 2015). Além disso, também é possível ver registros em subsuperfície de horizonte B espódico provenientes da crista de praia.

Os dados adquiridos terão por objetivo a obtenção da velocidade da onda eletromagnética da região para estudos futuros. Os resultados da linha adquirida, bem como a descrição de uma amostra retirada próxima à linha, serão mostrados.

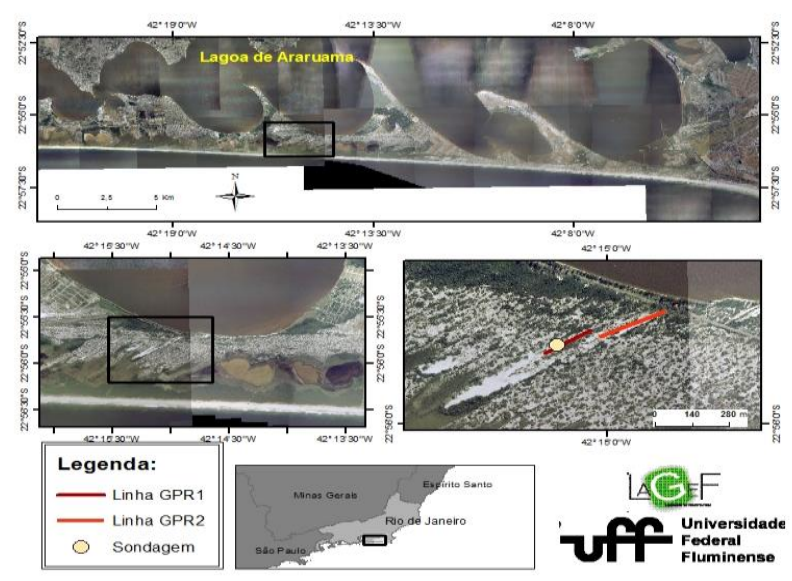

Figura 1: Mapa e localização da área de estudo e das linhas GPR e sondagem realizadas. 


\section{Metodologia/ Problema Investigado}

Para a aquisição dos dados brutos de GPR, foi utilizado o módulo SIR-3000 com roda disparadora, a fim de realizar a coleta de dados em modo contínuo, que mantém fixa a distância entre as antenas. O sistema de antenas usado nessa pesquisa foi o da GSSI, assim como os outros equipamentos, de $400 \mathrm{MHz}$ e blindado, sendo acoplado ao módulo e à roda por meio de cabos. Após serem conectados, o sistema GPR foi arrastado ao decorrer da direção da linha de forma manual. Para o processamento dos dados foi utilizado o software Radan 6.6 também da GSSI $\AA^{\text {e }}$ os passos desenvolvidos foram os de Background removal, filtro FIR (passa-banda de frequência) para a remoção de ruídos, ganho Range Gain. Também foi feita a conversão tempo-distância a partir do uso de uma linha CMP (common mid-point) regional, que é um método empregado para inferir a velocidade no meio em questão, realizada com antena de $80 \mathrm{MHz}$. Para fazer essa conversão de tempo para profundidade, a equação de two-way traveltime (TWTT) da trajetória do raio refletido depende da relação entre os valores da velocidade no meio, $\mathrm{V}$, da profundidade da interface de reflexão, $D$, e do deslocamento $T x-R x, x$, conforme mostrada abaixo.

$$
\operatorname{TWTT}(x)=\sqrt{\left(\frac{x}{V}\right)^{2}+\left(\frac{2 D}{V}\right)^{2}}
$$

Com isso, o valor da velocidade pode ser retirado da relação acima para a se obter uma maior acurácia da real profundidade de um alvo.

Para a coleta da amostra sedimentológica, foi utilizada uma sondagem manual, enterrando no solo, com o auxílio de um martelo, um cano de PVC até a profundidade de 3,35 $\mathrm{m}$ de material próximo à linha GPR. Essa investigação direta amarra o tempo em nanosegundos com o registro de profundidade adquiridos através do método geofísico indireto previamente coletados. O furo foi realizado em aproximadamente 140 metros a partir do início da linha GPR.

\section{Resultados}

No radargrama da linha GPR1 (Figura 2) é possível observar, primeiramente, a posição do lençol freático numa profundidade variando de aproximadamente 0,45 $\mathrm{m}$ a $0,70 \mathrm{~m}$ no decorrer do deslocamento. A sondagem realizada aos $140 \mathrm{~m}$ da linha, a profundidade do lençol freático foi de 0,65 $\mathrm{m}$ após a uma semana de intensa atividade pluviométrica na região. Por sua vez, no radargrama, a profundidade indicada para o lençol freático na posição referente à amostra foi de aproximadamente $0,50 \mathrm{~m}$. Entre $3,88 \mathrm{~m}$ e $4,7 \mathrm{~m}$ foi indicada a profundidade pelo horizonte da areia com matéria orgânica, considerado o horizonte $B$ espódico. Essa faixa implica numa atenuação no sinal do GPR, que passa a apresentar feições articuladas, devido aos metais na sua composição e presença de água salobra.
Essas características fazem com que essa camada seja eletricamente muito condutiva.

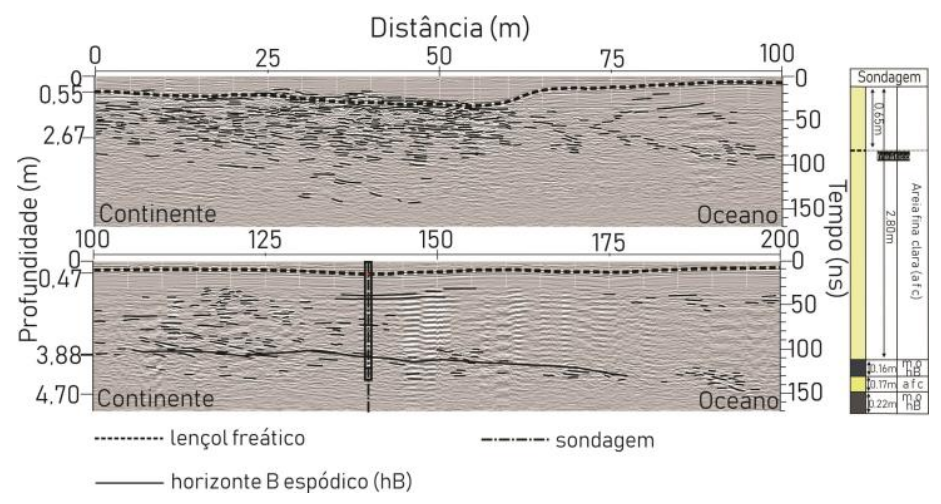

Figura 2: Linha GPR1 transversal à linha de costa e à lagoa realizada com antena de $400 \mathrm{Mhz}$ e com localização e breve descrição da sondagem realizada (Modificada de Radan 6.6).

A seção CMP (Figura 4) mostra o espectro de velocidade nas regiões de maior densidade de informação, sendo a maior delas adquirido o valor de velocidade efetiva de $0,071 \mathrm{~m} / \mathrm{ns}$. Para esse valor, a velocidade verdadeira foi de $0,078 \mathrm{~m} / \mathrm{ns}$, sendo esse atribuído ao lençol freático. Já para o pacote eólico e para o espodossolo foram adotados os valores de velocidade verdadeira de 0,065 $\mathrm{m} / \mathrm{ns}$ e $0,076 \mathrm{~m} / \mathrm{ns}$, respectivamente.

O testemunho retirado da área teve uma profundidade de $3,35 \mathrm{~m}$. Nos seus primeiros $2,8 \mathrm{~m}$ há a presença e areia fina clara, sendo que em $0,65 \mathrm{~m}$, o lençol freático aflora e essa areia mostra saturação por essa percolação do freático de águas sazonais proeminente de camadas superiores e pela decomposição de ácidos húmicos. A partir dos 2,8 m, nota-se uma faixa de aproximadamente $0,17 \mathrm{~m}$ de pacote escuro e mais compactado com matéria orgânica, sendo percebido também nos testemunhos SP-01 e SP-04 de Rocha (2013) onde a autora, em seu estudo, caracterizou o material como horizonte B espódico, contido nos espodossolos das cristas de praia (AGEITEC 2013). O horizonte espódico é formado por um processo pedogenético denominado de podzolização em que há transporte de $\mathrm{Fe}$ e $\mathrm{Al}$ e/ou matéria orgânica para o horizonte $\mathrm{B}$ e forma solos com $\mathrm{Bh}$, Bs ou Bhs. Esse tipo de solo possui $\mathrm{pH}$ menor que 7 e coloração escura. A coloração é de tom escuro, não só por causa da matéria orgânica presente, mas possivelmente pela presença de alumínio ácidos húmicos e ferro oxidados e uma baixa drenagem no solo. Além disso, Rocha (2013) definiu as amostras coletadas AMS1 e AMS-4 para datação por radiocarbono, referentes a esses testemunhos já citados, respectivamente, como depósitos praiais de idade Pleistocênica. Após esta faixa de matéria orgânica, uma nova faixa de cerca de 0,16 m com areia marrom claro surge e, depois, há a concentração de mais $0,22 \mathrm{~m}$ de novamente do material mais escuro. Esse intervalo pode ser proveniente de um retrabalhamento da laguna causada por processos costeiros de alta energia de regressão e transgressão 
Alves, R. C. R.; Santos, I.R.M.; Campos, P.M.V.; Fernandez, G. B.

marinha possivelmente no Quaternário. Registros sedimentares que possam gerar curvas de oscilações pleistocênicas são geralmente raros, já que esses indicadores não foram bem preservados com as mudanças do nível do mar no Pleistoceno.

Como não foi possível carregar o dado topográfico da linha GPR1, na Figura 3 a correção topográfica aplicada na linha GPR2 mostra a compatibilidade da profundidade do lençol freático com a linha GPR1 sem topografia.

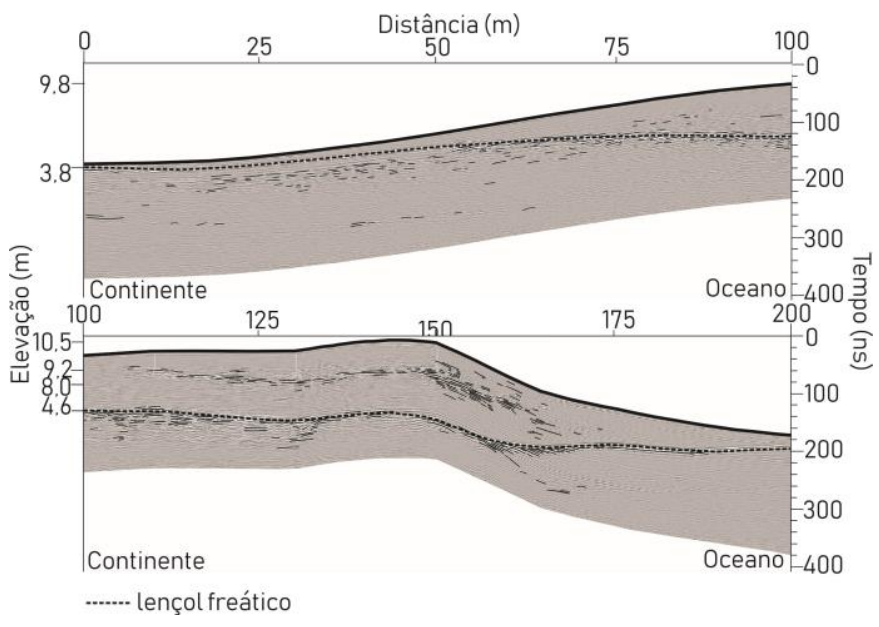

Figura 3: Linha GPR2 transversal à linha de costa e à lagoa realizada com antena de $400 \mathrm{Mhz}$ e com correção topográfica (Modificada de: Radan 6.6).
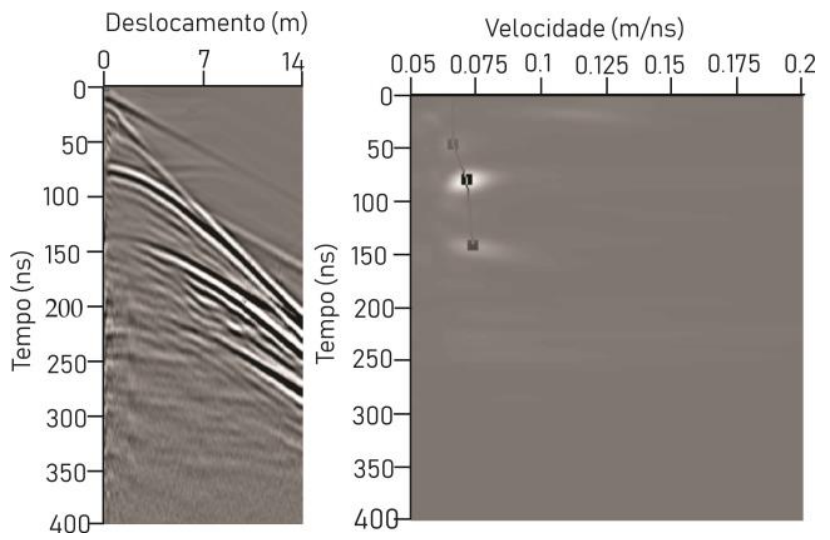

Flgura 4: Análise de velocidade para a seção CMP regional realizado com antena de $80 \mathrm{MHz}$ na área de estud (Modificado de: Radan 6.6)

\section{Discussão e Conclusões}

Os resultados encontrados dentro das linhas GPR foi possível estimar velocidades distintas a partir dos dados CPM realizado por Figueiredo (2018) a partir de sua integração com os dados de sondagem foi possível uma delimitação da zona Horizonte $B$ que pode vir a servir como camada guia de onda para futuras aquisições GPR dentro da área de estudo.

A profundidade do lençol freático mostrada pela sondagem de cerca de $0,50 \mathrm{~m}$ é aceitável comparada à mostrada pela investigação de GPR de 0,65. O modelo de velocidade encontrado para os 3 diferentes pontos foi de $0,065 \mathrm{n} / \mathrm{ms} ; 0,078 \mathrm{n} / \mathrm{ms}$ e $0,076 \mathrm{n} / \mathrm{ms}$ respectivamente. Essas velocidades tiveram uma boa correlação com a camada guia de onda (Horizonte B) após o processamento do radargrama e a análise da sondagem feita na área de estudo (Figura 2) em conjunto com suas propriedades físico-químicas. $\mathrm{O}$ lençol freático e o espodossolo tiveram velocidades semelhantes pelas suas características condutivas; sua saturação e a presença de ferro e matéria orgânica, respectivamente.

O GPR se mostrou uma importante ferramenta para identificar indiretamente o horizonte espódico $\mathrm{B}$, tendo em vista que esse tipo de camada não se preservou bem no litoral brasileiro com as mudanças de nível do mar.

A correção de tempo em profundidade possibilitada pelo CMP realizado na linha nas linhas GPR juntamente com a observação dos dados da sondagem, foi possível estimar a velocidade para o pacote e, de forma mais específica, para o lençol freático e o horizonte $B$ espódico. A integração dos resultados obtidos pelo GPR e sondagem foram fundamentais para uma melhor caracterização da velocidade da onda EM (GPR), para futuras campanhas dentro da área de estudo e também para suporte do processamento e caracterização de zonas anômalas geofísicas.

\section{Agradecimentos}

Os autores agradecem à Mariana Figueiredo (LAGEFUFF) pelo processamento dos dados de topografia, a CNPq e ao PIBIC pela bolsa de Iniciação Científica concedida à primeira autora.

\section{Referências}

Angulo, R. J.; Lessa, G. C.; Souza, M. C., 2006. A critical review of mid- to late-Holocene sea-level fluctuations on the eastern Brazilian coastline. Quaternary Science Reviews 25 p. $486-506$.

Coe Neto, R., 1984. Algumas considerações sobre a origem do sistema lagunar de Araruama. In: Lacerda. L.D. et al.(org.). Anais do Simpósio sobre Restingas Brasileiras. Universidade Federal Fluminense. P. 61-63.

Fernandez, G. B. \& Rocha, T. B,, 2015. Barreiras costeiras holocênicas: geomorfologia e arquitetura deposicional no litoral do Rio de Janeiro. Revista Brasileira de Geomorfologia. 16. 10.20502/rbg.v16i2.619.

Figueiredo, M. S., 2015. Geomorfologia e arquitetura deposicional da barreira holocênica no litoral entre Saquarema e Arraial do Cabo (RJ). 77f. 
Martin, L. \& Suguio, K., 1989. Excursion Route Along the Brazilian Coast between Santos (SP) and Campos (RJ). International Symposium on Global Changes in South America during the Quaternary. Special Publication no.2. $136 \mathrm{p}$.

Martin, L., Suguio, K., Dominguez, J. M. L.; Flexor, J. M., 1997. Geologia do Quaternário costeiro do litoral norte do Rio de janeiro e do Espírito Santo. CPRM Serviço Geológico do Brasil. 112p.

Muehe, D., 1984. Evidências de recuo dos cordões litorâneos em direção ao continente no litoral do Rio de Janeiro. In: Anais do Simpósio sobre Restingas Brasileiras, 1: 75-80 ill. EDUFF. Niterói, RJ.

Muehe, D. \& Corrêa, C.H.T., 1989. The coastline between Rio de Janeiro and Cabo Frio. In: Claudio Neves (ed.), Coastlines of Brazil, pp.110-123, American Society of Civil Engineers (ASCE), New York, NY, U.S.A. ISBN: 978-0872627079.

Rocha, T. B., 2013. A planície costeira meridional do complexo deltaico do rio Paraíba do Sul (RJ): arquiteutra deposicional e evolução da paisagem durante 0 Quaternário Tardio. 178f.: il. 